\title{
Foot and Ankle Surgery: The Indian Scenario in 2016
}

\author{
${ }^{1}$ Mandeep S Dhillon, ${ }^{2}$ John Ebnezar, ${ }^{3}$ Rakesh John
}

\begin{abstract}
In this review, we try to analyze the current scenario of foot and ankle surgery in India, with special emphasis on the problems faced by the indigenous population and also the challenges faced by foot and ankle surgeons of our country. Chronic infections of the foot (like tuberculosis, leprosy), neglected or mismanaged trauma cases (which usually result from a lack of awareness in the people regarding foot and ankle problems), foot and ankle problems faced by sportspersons, geriatric population, etc., form the crux of the discussion in this article.
\end{abstract}

Keywords: Foot ankle surgery, Geriatrics, Health care, Leprosy, Polio, Sports, Tuberculosis.

How to cite this article: Dhillon MS, Ebnezar J, John R. Foot and Ankle Surgery: The Indian Scenario in 2016. J Foot Ankle Surg (Asia-Pacific) 2017;4(1):40-44

Source of support: Nil

Conflict of interest: None

\section{INTRODUCTION}

India is a unique country not only for the fact that it is one of the most populous countries of the world but also one with a varied population with different habits, cultural beliefs, and practices. These beliefs and practices are reflected in the day-to-day lives of Indians and result in their own set of problems. The beliefs and practices are also seen in relation to injuries and other health care problems. Injuries and many other health problems are not often thought of as important and are frequently neglected. These injuries are of almost all the body parts, but the foot and ankle present a unique problem in itself as their injuries are commonly neglected.

Unique among the beliefs and practices of Indians is the consideration of the foot as an "object of beauty." The foot is often decorated by the women of all the communities and religious beliefs. Many a times, such decorations are limited to the special occasions

\footnotetext{
${ }^{1}$ Professsor and Head, ${ }^{2}$ Consultant, ${ }^{3}$ Senior Resident

1,3 Department of Orthopaedics, Postgraduate Institute of Medical Education and Research, Chandigarh, India

${ }^{2}$ Department of Orthopedics, Parimala Health Care Services Bengaluru, Karnataka, India

Corresponding Author: Rakesh John, Senior Resident Department of Orthopaedics, Postgraduate Institute of Medical Education and Research, Chandigarh, India, e-mail: rakeshjohn23@ gmail.com
}

like marriages and functions only, but often these are permanent as in tattoos seen among the tribal population of India.

Barefoot walking is also a feature probably unique in India and surrounding nations. This may be a result of economic constraints, as a large population of India still lives in deplorable socioeconomic conditions. Barefoot walking is seen not only among the rural population but also among the semiurban and urban populations. In many people, especially the old ones, this is a part of the way of life which they have been part of for a long time. Also, the religious beliefs in many religions followed in India mandate barefoot walking in the places of worship. While these habits help maintain the cleanliness of these places of worships, they may lead to injuries of the foot and ankle due to lack of protection afforded by the footwear.

This article tries to analyze the present scenario of foot and ankle injuries and their management in India. An analysis of problems that might be faced by the Indian population and the limited number of foot and ankle surgeons in India is discussed.

\section{LIMITED AWARENESS OF THE PROBLEM}

Awareness of foot and ankle injuries among the Indian population is very limited. It is not uncommon to see patients coming to outpatient clinics with deformed feet. Often patients tend to neglect the initial injury and continue with their activities only to present when they face problems in mobilizing or with their routine activities. Many times, they present with swollen feet with neglected metatarsal and tarsal fractures. Surprisingly, people tend to neglect open fractures of the foot and ankle also and present with infected wounds of the foot. Injuries to the feet of the children are also neglected and the outcomes at times are extreme. Interestingly, it is not only the patients who have a low level of awareness but the medical practitioners are also at fault in many instances. The level of awareness about the ankle and the foot injuries is usually inadequate among the general medical practitioners who unfortunately are the people who are the first point of medical contact for the general population. The level of importance provided by these practitioners to foot and ankle injuries is negligible. While fractures of the long bones are accorded some importance and managed expeditiously, such urgency is not accorded to foot and ankle injuries. Such injuries 
are often managed by bandaging or by applying Plaster of Paris casts. In the absence of adequate management of such injuries, patients often land up in having malunited fractures of the bones of the feet.

Not only injuries but also congenital deformities of the foot, like congenital talipes equinovarus (CTEV), congenital vertical talus, flat feet, etc., are often neglected by the parents, and it is not unusual to see a patient of neglected CTEV walking into the hospital on outer border of the feet in his/her teens. These problems are also due to superstitious beliefs in which the deformities are considered as a result of sins of the past life and due to supernatural forces. Parents neglect these congenital conditions and bring the patient to the orthopedic surgeon when the child is debilitated or reaches marriageable age. Such feet are often a nightmare for the surgeon as permanent changes usually have set in for both the bones and the soft tissues. Management is long and results are variable.

\section{DIFFICULT AND NEGLECTED TRAUMA}

Trauma to the foot and ankle in Indian population is at times unique in its mode of occurrence. It is not infrequent to see people, especially children, presenting with injury caused by the bicycle spoke and cycle rickshaw. ${ }^{1,2}$ Cycle rickshaw and bicycle are common modes of transportation in India, both in the rural and the suburban injuries. Children sitting on the bar connecting the handle and the seat is a common side. Agarwal and Pruthi ${ }^{2}$ have described in detail the possible mechanisms of injury in their study. They found that the posterior area of the ankle $(n=30)$ was the most commonly affected site, followed by the medial midfoot $(n=7)$ and the forefoot $(n=3)$. Soft tissue injury was a prominent component of most of the injuries, and the area around the Achilles tendon was injured in $63 \%$ of the patients.

Jaiswal et $\mathrm{al}^{1}$ reported that children below 15 years of age were the main victims of bicycle and cycle rickshawrelated injuries. It was also reported that soft tissue injuries were the predominant injuries among those children. Fractures tended to be involving the physis in majority of the cases.

Another interesting mode of injury to the Achilles tendon involves the use of Indian-style toilet that needs a squatting position for defecation. Many a times, secondary to slippery nature of the toilet, the foot tends to slip off into the pan and the area around the Achilles tendon is injured. Dar et $\mathrm{al}^{3}$ reported a series of 12 patients who sustained toilet seat injury. While abrasion was a common finding in all the patients, eight patients had complete tear of the Achilles tendon and four had partial tears. All patients underwent primary repair with satisfactory outcomes.
The lack of discipline in following traffic rules and rash driving is responsible for presentation of a large number of foot and ankle injury among the pedestrian population. Trauma centers in India see a large number of people presenting with complex midfoot and forefoot injuries whose management is difficult and prolonged and outcomes are not that good. Many of these injuries can be labeled as crushed foot injuries and often need amputation of the foot, as they may be nonsalvageable. Unfortunately, limited data are available in Indian literature about these injuries. Dhillon et $\mathrm{al}^{4}$ published the result of their epidemiological study of foot injuries in India and found that road traffic accident was the most common mode of foot injuries and the outcomes were dependent on the severity at the time of presentation.

\section{DIABETIC FOOT: A MAJOR PROBLEM}

With increasing life expectancy of the population and with an increase in the income and spending power, the Indian population is now facing diseases that were previously uncommon. Sedentary lifestyle, lack of exercise, and influx of dietary practices of developed nations have led to an exponential increase in the diabetic population. Diabetes is not given adequate consideration by most of the patients and is often managed carelessly. Patients frequently discontinue dietary restrictions and even oral hypoglycemics on their own and predispose themselves to complications of diabetes.

Diabetic foot was noted to be the second most common complication among the diabetics (seen in 32.7\%) in the study by Mohan et $\mathrm{al}^{5}$ among 6,168 diabetics included in their study. The barefoot walking habits, using open footwear like sandals and chappals and not using shoes also make the Indian diabetic population vulnerable to trivial to severe injuries. ${ }^{6,7}$ The very fact that diabetic neuropathy makes the foot and ankle area insensate also predisposes to severe injuries. Scratches and abrasions often get converted to nonhealing ulcers. Osteomyelitis of the foot bones with multiple discharging sinuses is also not unheard of. All these factors decrease the chances of salvaging the foot.

Chandalia et $\mathrm{al}^{6}$ noted in their study the high frequency of peripheral neuropathy and low frequency of peripheral vascular disease in the Indian diabetic and concluded that good foot care practices might be expected to be highly successful. Evaluation done by the authors in their study brought forward the poor educational status of Indian diabetics. They also noticed poor motivation to maintain optimum glycemic control, negligent attitude toward injury, infection, and other symptoms related to the feet among the patients and concluded that even though the average education in their study cohort was good, there was a noticeable apathy toward foot care 
and diabetes management among the subjects. Similar conclusions about the educational and socioeconomic conditions of Indian diabetics and the level of awareness toward foot care were drawn by Viswanathan et al. ${ }^{8}$

Viswanathan ${ }^{9}$ reported a difference in the epidemiological characteristics between the diabetics in India and the Western countries, notable among which was the high prevalence of neuropathy among Indians and of peripheral vascular disease among the Western population. This was similar to the conclusions drawn by Chandalia et al. ${ }^{6}$

\section{TUBERCULOSIS AND INFECTIONS OF FOOT AND ANKLE}

Tuberculosis is still a major problem in developing nations like India. While pulmonary tuberculosis is the most common form of this disease, skeletal tuberculosis cases are also common in developing and Third World countries. Foot and ankle tuberculosis is a rare form of skeletal tuberculosis and is reported in the literature mainly as case reports and series. ${ }^{10-16}$ Tuberculosis of the foot and ankle presents often by mimicking many other foot and ankle pathologies and hence, poses a diagnostic challenge for the clinician. Considering that early diagnosis and initiation of early and effective antitubercular treatment is essential for managing skeletal tuberculosis, a high rate of suspicion on the part of the treating physician is a must to diagnose such cases. Any patient presenting with long-standing pain/swelling/discharging sinus in the foot and ankle region without any obvious etiology should be considered to have tuberculosis of foot and investigated in that line. Of the 74 cases reviewed by Dhillon and Nagi, ${ }^{13}$ the calcaneus was involved most commonly, followed the midtarsal joints, Lisfranc joints, and ankle. Commonest radiologic finding was that of rarefaction, but osteolytic variety has also been described in the literature. ${ }^{14}$ Thus, the first step of investigation, i.e., a radiograph of the foot and ankle, should initiate the thought process for a possible diagnosis of tuberculosis. Corroborative investigations like erythrocyte sedimentation rate, total leukocyte count, and Mantoux test must also be obtained. Other investigations, like tuberculosis-polymerase chain reaction, enzyme-linked immunosorbent assay, and open biopsy, may also be needed for arriving at a diagnosis. Culture often comes out to be negative in these cases as these are pauci-bacillary type of tuberculosis with low bacterial loads.

In summary, tuberculosis of the foot and ankle though rare is an entity worth suspecting in chronic foot and ankle problems and need to be managed on a priority basis to prevent the associated debility.

Osteomyelitis of foot and ankle is also a common problem that frequently is secondary to other etiologies like diabetic foot or secondary to open fractures of the foot bones. Management is primarily aimed at controlling the infection with appropriate antibiotics.

\section{POLIOMYELITIS AND LEPROSY}

Poliomyelitis, which was rampant in India a few decades back, has now become a thing of the past, with the World Health Organization declaring India as polio free. Polio came with its own set of problems in the form of deformities of multiple joints secondary to residual paralysis and needed surgical procedures ${ }^{17,18}$ for correction of deformities and to enable the patient some useful mobility, but now they are almost never performed and the new age orthopedic residents have not even seen these procedure being done.

Leprosy is still a major problem in India caused by the lesser known of the two mycobacteria - Mycobacterium leprae. This condition often leads to foot drop, disfiguring of the foot with loss of digits, clawing, and presence of sores as the few commonly seen problems. Leprosy causes the foot to become insensate and leads to Charcot's foot (similar to diabetic arthropathy) and also to the destruction of the joints of the foot.

\section{INJURIES OF FOOT AND ANKLE IN SPORTSMEN}

With an increase in the professional and recreational sporting activities, sports-related injuries have increased in the public. These injuries also involve the foot and ankle regions and are a common cause of keeping the sportsmen sidelined from sporting activities. Data regarding incidence of such injuries in Indian sportsmen are lacking. There are only a few studies evaluating these injuries. Dhillon et $\mathrm{a}^{19}$ have reviewed the available literature on foot and ankle injuries in cricket. They have noted that the bowlers are more commonly affected than the batsmen. Though probably cricket is the most popular sport in India, foot and ankle injuries are seen in other sports like soccer, hockey, volleyball, basketball, kabaddi, etc.

\section{FOOT AND ANKLE PROBLEMS IN GERIATRIC AGE GROUPS}

Foot and ankle problems, both traumatic and nontraumatic, are on the rise because of increased lifespan the world over. In America, 20\% of the surgical admissions are of geriatric patients. ${ }^{20}$ The ankle and foot problems in the young and the middle aged are neglected over the years, and these present as fixed deformities in the geriatric age group, which most of the times are nonsalvageable. ${ }^{20}$ Since foot problems lower the mobility in old age, it may indirectly lead to the increase in comorbidities like diabetes, heart disease, hypertension, 
ischemic heart disease, and osteoporosis and may significantly reduce the quality of life in elders. Foot injuries in elderly are on the rise because of increased demands of exercises and physical activities needed to keep oneself fit in old age, toilet-related falls and injuries (notably the tendoachilles injuries), falls due to poor balance, coordination, ear, eyesight problems, etc. This may lead to ankle and foot injuries, most frequently being ankle sprains and in rare situations low-energy fractures around the ankle. Managing these injuries is a challenge for an orthopedic surgeon as the approach and skills needed are different.

Other nontraumatic foot and ankle problems, like calcaneal spurs, retrocalcaneal spurs, plantar fasciitis, atrophy of the heel pad, foot deformities like hallux valgus, neglected foot problems like flat foot, CTEVs, etc., can pose diagnostic and therapeutic challenges. Problems like nonhealing ulcers due to diabetes, thromboangiitis obliterans, varicose veins, leprosy, and repetitive minor injuries due to improper footwear leading to foot ulcers can all be very difficult to tackle. Now arthritis of the ankle and foot joints and even malignancies are on the rise. Dealing with foot and ankle problems in geriatric age groups needs a different approach as these patients have physiologic and age-related changes and problems, have associated multiple comorbidities and comusculoskeletal problems that need the involvement of doctors from multiple specialties. An orthopedic surgeon has to work with a team of geriatricians, physicians, anesthetists, etc. to give satisfactory results to their problems. Another aspect to be dealt with is the deteriorating mental and emotional health in these age groups which leads to depression, anxiety, etc. that can hamper the best intentions of an orthopedic surgeon.

The answer lies in creating widespread awareness about the increasing incidences of ankle and foot problems in the geriatric age patients and the value of prevention and promotion of good foot care in the younger people to avoid problems in later life. Orthopedic surgeons need to gear up to the challenges of managing these geriatric foot problems in old age. Specialized skills, both nonoperative and operative, need to be developed by changing the mind set and acquiring adequate training to handle these problems successfully in old age. Ankle and foot replacement surgeries are also on the rise and one needs to focus more on proper diagnosis and treatment in elderly age group to give them a good quality of life in their twilight years.

\section{FOOT AND ANKLE INJURIES FROM A HEALTH CARE PROSPECTIVE}

In view of the above-discussed problem, the management of foot and ankle problems in India is also difficult.
The orthopedic surgeon is frequently referred to cases which have been delayed or neglected and then the management becomes full of decision-making dilemmas. Economic constraints and the relative lack of investigations like computed tomography scans and magnetic resonance imaging, which are considered bare minimum investigations for complete evaluation of the problem, tend to aggravate the situation. Moreover, there are few focused foot and ankle orthopedic surgeons. Most of the surgeons attach trivial importance to the foot and ankle, and quite often the fracture management is left to the junior-most person of the team. Surgeries on the foot and ankle when performed without a clear understanding of the anatomy and the biomechanics may be disastrous. Placement of hardware without adequate reduction of the fracture produces malunited fractures that bring the problems of altered biomechanics and tend to produce early osteoarthritic changes.

But working in the midst of deficiency also produces some innovations that can have beneficial effects on the foot and ankle management in developing countries, an example of which could be the Shetty test described by Shetty et al, ${ }^{21}$ which can screen patients with suspected ankle injuries with good specificity and sensitivity in minutes even without the use of radiographs, thus enabling the surgeon to give adequate attention to those who actually need it. Another notable example of the Indian jugaad technique could be the catapult splint described by Jain et al, ${ }^{22}$ which was made from discarded car tubes and acted to prevent equines deformity of foot in patients who have undergone Ilizarov/external fixator application procedures for the lower limb. This catapult splint acts as an active as well as a passive splint to prevent the foot from going into equinus. A chappal attached with cotton bandage to the fixator frame can function as a static splint to serve the same purpose.

Despite limitations, the foot and ankle scenario is set to look forward with the ever greater interest shown by the orthopedic surgeons in learning the tricks of the trade, as is evident by the large gathering seen in dedicated sessions on foot and ankle in national and international conferences.

\section{REFERENCES}

1. Jaiswal A, Nigam V, Jain V, Kapoor S, Dhaon BK. Bicycle and cycle rickshaw injury in suburban India. Injury 2006 May;37(5):423-427.

2. Agarwal A, Pruthi M. Bicycle-spoke injuries of the foot in children. J Orthop Surg (Hong Kong) 2010 Dec;18(3):338-341.

3. Dar TA, Sultan A, Dhar SA, Ali MF, Wani MI, Wani SA. Toilet seat injury of the Achilles tendon a series of twelve cases. Foot Ankle Surg 2011 Dec;17(4):284-286.

4. Dhillon MS, Aggarwal S, Dhatt S, Jain M. Epidemiological pattern of foot injuries in India: preliminary assessment of 
data from a tertiary hospital. J Postgrad Med Edu Res 2012 Jul;46(3):144-147.

5. Mohan V, Shah SN, Joshi SR, Seshiah V, Sahay BK, Banerjee S, Wangnoo SK, Kumar A, Kalra S, Unnikrishnan AG, et al.; DiabCare India 2011 Study Group. Current status of management, control, complications and psychosocial aspects of patients with diabetes in India: Results from the DiabCare India 2011 Study. Indian J Endocrinol Metab 2014 May;18(3):370-378.

6. Chandalia HB, Singh D, Kapoor V, Chandalia SH, Lamba PS. Footwear and foot care knowledge as risk factors for foot problems in Indian diabetics. Int J Diabetes Dev Ctries 2008 Oct;28(4):109-113.

7. Pendsey S. Epidemiological aspects of diabetic foot. Int J Diabetes Dev Ctries 1994;14:37-38.

8. Viswanathan V, Shobhana R, Snehalatha C, Seena R, Ramachandran A. Need for education on footcare in diabetic patients in India. J Assoc Physicians India 1999 Nov;47(11): 1083-1085.

9. Viswanathan V. The diabetic foot: perspectives from Chennai, South India. Int J Low Extrem Wounds 2007 Mar;6(1): 34-36.

10. Dhillon MS, Sharma S, Gill SS, Nagi ON. Tuberculosis of bones and joints of the foot: an analysis of 22 cases. Foot Ankle 1993 Nov-Dec;14(9):505-513.

11. Dhillon MS, Singh P, Sharma R, Gill SS, Nagi ON. Tuberculous osteomyelitis of the cuboid: a report of four cases. J Foot Ankle Surg 2000 Sep-Oct;39(5):329-335.
12. Dhillon MS, Tuli SM. Osteoarticular tuberculosis of the foot and ankle. Foot Ankle Int 2001 Aug;22(8):679-686.

13. Dhillon MS, Nagi ON. Tuberculosis of the foot and ankle. Clin Orthop Relat Res 2002 May;(398):107-113.

14. Dhillon MS, AggarwalS, Prabhakar S, Bachhal V. Tuberculosis of the foot: an osteolytic variety. Indian J Orthop 2012 Mar;46(2):206-211.

15. Nayak B, Dash RR, Mohapatra KC, Panda G. Ankle and foot tuberculosis: a diagnostic dilemma. J Family Med Prim Care 2014 Apr;3(2):129-131.

16. Mittal R, Gupta V, Rastogi S. Tuberculosis of the foot. J Bone Joint Surg Br 1999 Nov;81(6):997-1000.

17. Dhillon MS, Sandhu HS. Surgical options in the management of residual foot problems in poliomyelitis. Foot Ankle Clin 2000 Jun;5(2):327-347.

18. Rodriguez RP. Surgical reconstruction of the paralytic flaccid foot. Foot Ankle Clin 2000 Jun;5(2):349-379, vii.

19. Dhillon MS, Prabhakar S, Dhillon H, Bachhal, V. Foot and ankle injuries in cricket: a review. J Foot Ankle Surg 2011 Dec;XXVI(2).

20. Hirsch $\mathrm{CH}$. When your patient needs surgery: weighing risks versus benefits. Geriatrics 1995 Jan;50(1):26-31.

21. Shetty V, Wasnik S, Hegde C, Shetty V, Kasture S, Thakur H. The "Shetty test" in ankle injuries: validation of a novel test to rule out ankle fractures. Eur J Orthop Surg Traumatol 2013 Oct;23(7):831-833.

22. Jain V, Agrawal M, Dhal A. Catapult splint: a foot dorsiflexion assist splint. Foot Ankle Surg 2011 Dec;17(4):312-314. 